\title{
The Evolution of the US
}

Family Income-Schooling Relationship and Educational Selectivity

CHRISTIAN BELZIL JÖRGEN HANSEN 


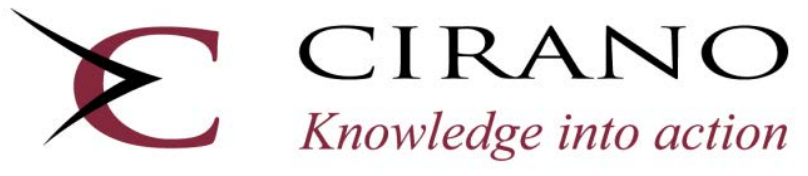

Center for Interuniversity Research and Analysis on Organizations

The purpose of the Working Papers is to disseminate the results of research conducted by CIRANO research members in order to solicit exchanges and comments. These reports are written in the style of scientific publications. The ideas and opinions expressed in these documents are solely those of the authors.

Les cahiers de la série scientifique visent à rendre accessibles les résultats des recherches effectuées par des chercheurs membres du CIRANO afin de susciter échanges et commentaires. Ces cahiers sont rédigés dans le style des publications scientifiques et n'engagent que leurs auteurs.

CIRANO is a private non-profit organization incorporated under the Quebec Companies Act. Its infrastructure and research activities are funded through fees paid by member organizations, an infrastructure grant from the government of Quebec, and grants and research mandates obtained by its research teams.

Le CIRANO est un organisme sans but lucratif constitué en vertu de la Loi des compagnies du Québec. Le financement de son infrastructure et de ses activités de recherche provient des cotisations de ses organisations-membres, d'une subvention d'infrastructure du gouvernement du Québec, de même que des subventions et mandats obtenus par ses équipes de recherche.

\section{CIRANO Partners - Les partenaires du CIRANO}

Corporate Partners - Partenaires corporatifs

Autorité des marchés financiers

Bank of Canada

Bell Canada

BMO Financial Group

Business Development Bank of Canada

Caisse de dépôt et placement du Québec

Desjardins Group

Énergir

Hydro-Québec

Innovation, Science and Economic Development Canada

Intact Financial Corporation

Manulife Canada

Ministère de l'Économie, de la Science et de l'Innovation

Ministère des finances du Québec

National Bank of Canada

Power Corporation of Canada

PSP Investments

Rio Tinto

Ville de Montréal

Academic Partners - Partenaires universitaires

Concordia University

École de technologie supérieure

École nationale d'administration publique

HEC Montréal

McGill University

National Institute for Scientific Research

Polytechnique Montréal

Université de Montréal

Université de Sherbrooke

Université du Québec

Université du Québec à Montréal

Université Laval

CIRANO collaborates with many centers and university research chairs; list available on its website. Le CIRANO collabore avec de nombreux centres et chaires de recherche universitaires dont on peut consulter la liste sur son site web.

(c) June 2020. Christian Belzil, Jörgen Hansen. All rights reserved. Tous droits réservés. Short sections may be quoted without explicit permission, if full credit, including (C) notice, is given to the source. Reproduction partielle permise avec citation du document source, incluant la notice C.

The observations and viewpoints expressed in this publication are the sole responsibility of the authors; they do not necessarily represent the positions of CIRANO or its partners. Les idées et les opinions émises dans cette publication sont sous l'unique responsabilité des auteurs et ne représentent pas nécessairement les positions du CIRANO ou de ses partenaires. 


\title{
The Evolution of the US Family Income-Schooling Relationship and Educational Selectivity *
}

\author{
Christian Belzil †, Jörgen Hansen *
}

\begin{abstract}
Résumé
We estimate a dynamic model of schooling on two cohorts of the NLSY and find that, contrary to conventional wisdom, the effects of real (as opposed to relative) family income on education have practically vanished between the early 1980's and the early 2000's. After conditioning on a cognitive ability measure (AFQT), family background variables and unobserved heterogeneity (allowed to be correlated with observed characteristics), income effects vary substantially with age and have lost between $30 \%$ and $80 \%$ of their importance on age-specific grade progression probabilities. After conditioning on observed and unobserved characteristics, a $\$ 300,000 \mathrm{di}$ erential in family income generated more than 2 years of education in the early 1980 's, but only one year in the early 2000's. Put differently, a $\$ 70,000$ differential raised college participation by 10 percentage points in the early 1980's. In the early 2000's, a $\$ 330,000$ income differential had the same impact. The effects of AFQT scores have lost about $50 \%$ of their magnitude but did not vanish. Over the same period, the relative importance of unobserved heterogeneity has expanded significantly, thereby pointing toward the emergence of a new form of educational selectivity reserving an increasing role to noncognitive abilities and/or preferences and a lesser role to cognitive ability and family income.
\end{abstract}

Keywords/Mots-clés: Inequality, Education, Family Income

JEL Codes/Codes JEL: I2, J1, J3

\footnotetext{
* Financial support from Investissement d'Avenir (ANR-11-IDEX-0003/ Labex Ecodec/ANR-11-LABX-0047) and Social Sciences and Humanities Research Council of Canada (grant 435-2017-0129) is gratefully acknowledged. We thank Philippe Belley, Evgenia Dechter, Lance Lochner, Michael Lovenheim, Arnaud Maurel, Douglas Webber, and participants at the IAAE 2018 Conference (Montreal) and the ESEM 2019 (Manchester) for comments and exchanges. We also thank Ed Vytlacil and four anonymous referees for their insightful comments. The usual disclaimer applies.

${ }^{\dagger}$ CREST, CNRS, Paris Polytechnic Institute and IZA and CIRANO

$¥$ Concordia University, CIREQ, CIRANO and IZA
} 


\section{Introduction and Motivation}

In recent years, a relatively large number of papers have studied the evolution of education inequalities between high-income and low-income classes in the US. While some have stressed the existence of an increasing gap between top and bottom quartiles (Belley and Lochner, 2007, Lochner and Monge-Naranjo, 2012, Avery and Kane, 2004 and Bailey and Dynarski, 2011), others have reported a more stable relationship (Kinsler and Pavan, 2011 and Chetty et al., 2014). ${ }^{1}$

In this paper, we take a different path than most of the existing literature and investigate the evolution of the effects of real family income (as opposed to relative income) on education outcomes. We show that income effects have practically vanished between the 1980's and the early 2000's and that the effects of AFQT scores have also decreased.

To do so, we estimate a dynamic model of schooling with unobserved heterogeneity on two cohorts of the National Longitudinal Survey of Youth (the 1979 cohort and the 1997 cohort) and compare the evolution of the effects of family income and Armed Forces Qualification Test (AFQT) scores on agespecific grade progression probabilities and resulting educational outcomes (years of schooling and college participation).

Our approach differs from the existing literature in three main dimensions. First, we measure the change in the effect of real income as opposed to the evolution of education gaps between high-income and low-income sub-populations. The evolution of the effect of parental income on higher education is impossible to infer solely from results emphasizing the role of relative income because the latter are potentially imputable to both a change in income distribution (creating an income effect) as well as a change in the effect of real family income which could be driven by a change in the cost or in some of its determinants.

While it is widely recognized that income growth has been more significant among upper income classes, and that the sticker price of four-year colleges has also increased faster than inflation, other institutional changes affecting higher education decisions may have tempered the effects of income inequality and tuitions and thereby reduced the effect of real income.

As documented in Page and Scott-Clayton (2015) and in Dynarski and Scott-Clayton (2013), there has been a significant increase in state and fed-

\footnotetext{
${ }^{1} \mathrm{~A}$ more thorough review of the literature, along with motivation arguments, are found in an appendix located in a supplementary file.
} 
eral financial aid programs. Many of those have been designed in order to reduce the cost of college for low income people (Belley et al., 2014). At the same time, tax regulations have contributed to drive the net price of two-year colleges close to zero (Abel and Deitz, 2014). Also, and as documented in Hoxby (2009), the substantial increase in college enrollments observed between the early 1980's and the early 2000's was mostly due to increased capacity at lower quality (and lower tuition) institutions. Finally, many papers in the structural literature have stressed that education choices are largely explained by a non-pecuniary dimension (the consumption value). If its importance has expanded relatively more among lower income sub-populations than among high income families (already endowed with a high taste for education), it could substantially damp the effect of tuition increases. For all these reasons, the evolution of real family income effects remains an open question. ${ }^{2}$

A second difference is that we allow income effects to vary with age within each cohort using 3 different intervals; from 16 to 18, from 19 to 21, and from 22 to $25 .^{3}$ There are good reasons for making a distinction between agespecific income effects. At age 16, individuals progress toward high school graduation and are fully dependent of their parents. At age 19, individuals are likely to still be dependent of their parents but start experiencing early college transitions that are more costly. At age 22, grade transitions are less frequent and individuals are likely to be less dependent. ${ }^{4}$ As the degree of dependence on parental income may change substantially as individuals are aging, it is conceivable that the overall relationship between family income and schooling is driven by some age-specific dependence. On top of this, the parent-child relationship may have evolved over the period of time elapsed between the 1979 and the 1997 cohorts, and it is particularly important to know if changes in income effects across cohorts have been spread uniformly between late teenage years and early adulthood.

Finally, a third difference which turns out to be fundamental, is that we control for dynamic selection within each cohort and therefore separate

\footnotetext{
${ }^{2}$ The increasing effect of parental income on educational outcomes is invoked as one of the main motivations for incorporating credit (liquidity) constraints within structural models of human capital accumulation. This is the case in Lochner and Monge-Naranjo (2010), Johnson (2013), Abbott et al (2016) and Hai and Heckman (2017).

${ }^{3}$ In our terminology, and to take an example, a transition at age 16 refers to a grade change (or lack thereof) from 16 to 17. In our data, the last transition is from 25 to 26 .

${ }^{4}$ Note that according to US federal financial aid regulations (FAFSA), an individual becomes automatically independent from the parents only at age 24 .
} 
changes in the effects of real income, AFQT and family characteristics from potential movements in the distribution of unobservables. Note that these last two dimensions of our analysis (the effect of aging on grade transitions and the incorporation of unobserved heterogeneity) may not be tackled with standard linear regression models.

Throughout the paper, we use the term "unobserved heterogeneity" to designate any unmeasured factor such as taste for schooling, monetary or non-monetary costs of education or ability and motivation, which remains significant after controlling for AFQT scores, non-cognitive skill measures such as the Rotter Locus of Control (measuring the internal control of an individual) and the Rosenberg Self-Esteem Scale (measuring the degree of approval toward oneself), and other characteristics. Although those noncognitive skill measures are observed in the NLSY79 only, we develop an approach that makes use of a predicted non-cognitive skill component using individual and family characteristics observed in both cohorts. We then allow for unobserved heterogeneity (unobserved type probabilities) to depend on predicted non-cognitive skill measures. These measures being themselves correlated with family background variables, family income and AFQT's, we need not assume orthogonality between unobserved heterogeneity and measured characteristics such as income.

Documenting the importance of dynamic selection is crucial. First, if choices are truly sequential and unobserved heterogeneity is important within a given cohort, ignoring it is likely to bias income and AFQT effects measured within a given cohort. On top of this, if the relative importance of unobserved heterogeneity changes across cohorts, any comparison between marginal effects of income obtained from OLS estimates across different cohorts becomes completely uninformative even if income is an exogenous regressor (or subject to some randomization procedure at the start of the process)..$^{5}$

The incidence of changes in educational selectivity has also attracted attention among those involved in education policies. According to the National Center for Education statistics, the yearly flow of individuals graduating with a Bachelor's degree has fluctuated between 1.5 and 3.0 million per year between 2005 and 2018. These numbers are far in excess of those

\footnotetext{
${ }^{5}$ The notion of dynamic selection plays a key role in many areas of economics and econometrics. Its statistical implications are discussed in Lancaster (1990) in the context of duration and transition data analysis and in Cameron and Heckman (1998) within an optimal schooling model. We provide an intuitive illustration in the section "Background Material" found in a supplementary file.
} 
for the early 1980's. ${ }^{6}$ Because this large increase in enrollments was more common at lower quality institutions, this has most likely driven important changes in the educational selection process and contributed to a reduction in higher education selectivity. It is therefore important to take this into account when measuring the evolution of income effects.

Following the existing literature, we adopt a nonstructural (or a semistructural) approach to the extent that we treat family income and other individual and family characteristics as exogenous regressors. This means that we can actually measure the reduced-form effect of real income on grade attainment at any specific age of interest and compare it directly with results obtained from regression methods and which have been reported in the existing literature.

The main findings are the following. Contrary to conventional wisdom, there is no evidence that real family income has become a more important determinant of higher education. Our results indicate that point estimates of the effects of family income on grade progression, highest grade completed and college participation have practically vanished. Between the early 1980's and the early 2000's, income effects have lost between $30 \%$ and $80 \%$ of their importance on grade transition probabilities, depending on age and family income at which those are measured. As indicated by their standard errors, the effects of income and AFQT are as precisely estimated in both cohorts, but income effects are often not significantly different from 0 in the 1997 cohort. Even if their differences across cohorts are not always statistically significant, there is virtually no age level and no income level at which income and AFQT effects have increased over time.

In the 1979 cohort, a $\$ 10,000$ difference in income raised the probability of grade progression at age 19 by 0.016 , highest grade attainment (at age 25 ) by 0.073 year and the population proportion of college enrollees by 1.4 percentage point. In the 1997 cohort, the same real income difference raised grade progression probability by 0.004 , highest grade completed at age 25 by 0.027 year and college participation by 0.3 percentage point. As a result, and after conditioning on observed and unobserved characteristics, a $\$ 300,000$ differential in family income generated more than 2 years of education in the early 1980's, but only one year in the early 2000's. Put differently, a $\$ 70,000$ family income differential raised college participation by 10 percentage points in the early 1980's. In the early 2000's, a $\$ 330,000$

\footnotetext{
${ }^{6}$ Source: 120 years of American Education: A Statistical Portrait, National Center for Education Statistics, 1993.
} 
income differential had the same impact on college participation. Despite the growing frequencies of belated grade progression (those taking between 22 and 25) between the 1980's and the early 2000's, transitions taking place beyond 22 appear to be entirely disconnected from family income in both cohorts.

Either in the early 1980's or in the early 2000's, AFQT scores have been the most important observed determinant of grade progression and education outcome in the NLSY. However, and aside from pre-college transitions, the effects of AFQT scores on grade transitions have also decreased between the 1980's and the early 2000's. A $1 / 3$ standard deviation increase in AFQT raised grade progression probability by 0.050 at age 20 in the 1979 cohort but by only 0.016 in the 1997 cohort. The marginal effects for the older cohort translated into increases of 0.16 year of schooling at age 20 and 0.324 at age 25 . In the early 2000's, the corresponding marginal effects had dropped to 0.084 (at age 20) and 0.143 (at age 25). For belated college transitions, the AFQT effects dropped from 0.035 to 0.008. All in all, the effects of AFQT scores on schooling attainments measured at any point between age 19 and 25 have been reduced by more than $50 \%$ between the early 1980 's and the early 2000's.

It is important to note that the disappearance of parental income and AFQT score effects are neither the by-product of the allowance for a correlation between unobserved heterogeneity and family income, nor dependent on extreme income levels. Results obtained with orthogonal unobserved heterogeneity are similar and others obtained when removing the top and bottom $1 \%$ income levels also disclose the same patterns.

Our findings suggest an interesting phenomenon. Classical educational selection based partly on cognitive abilities and/or family income (present in the 1979 cohort) is being gradually dominated by a different form of selection which reserves a more important role to non-cognitive abilities and/or preferences and a lesser role to cognitive ability and family income. ${ }^{7}$ Put differently, the evolution of income and AFQT score effects indicate that college expansion has benefitted mostly lower income and lower ability individuals. Indeed, the decrease in the effect of real income on higher education has most likely been sufficiently strong to counteract the increase in income dispersion and thereby prevent an increasing education gap between high

\footnotetext{
${ }^{7}$ Interestingly, Deming (2017) analyzes changes in the wage returns to skills using the NLSY79 and NLSY97 and finds that labor market return to social skills was much greater in the 2000s than in the mid 1980s and 1990s.
} 
and low family income families.

Not accounting for dynamic selection would inflate income effects on both grade progression probabilities and schooling attainments. Because unobserved heterogeneity is found to be relatively more important in the early 2000's, the inflation would be more serious for the 1997 cohort. While ignoring unobserved heterogeneity would still reveal decreasing income effects, it would do so from inaccurate within-cohort income effect estimates. Moreover, ignoring dynamic selection would hide the fact that income effects have practically vanished.

The remaining sections of the paper are structured as follows. In Section 2, we describe the data. In Section 3, we present our econometric model. In the following section, we describe the evolution of the marginal effects of income and AFQT scores. In Section 5, we illustrate the implications of ignoring dynamic educational selectivity. In the final section, we present a summary of the results along with some economic interpretation and avenues for future research.

\section{The NLSY79 and NLSY97 Cohorts}

Our analysis is based on data from two cohorts of the National Longitudinal Survey of Youth, NLSY79 and NLSY97. The NLSY is one of the most commonly used data set in the US. Because we basically follow the same selection criteria as those laid-out in papers mentioned earlier (Belley and Lochner, 2007, Kinsler and Pavan, 2011, and others), we provide details about sample selection in an appendix found in a supplementary file.

As is common in the earlier literature, we use AFQT scores to control for cognitive ability. AFQT scores are an average of 4 components of the Armed Services Vocational Aptitude Battery (ASVAB) and should therefore contain a lesser measurement error level than each component introduced separately. ${ }^{8}$ We use scores provided by Altonji et al. (2012) which are adjusted to improve comparability across cohorts. To take into account differences in AFQT's that could be explained by differences in education and age when it was measured, we regress AFQT scores on age and education and use the standardized value of the residual as the cognitive ability indicator.

For each individual, we measure schooling attainment as indicated by

\footnotetext{
${ }^{8}$ The AFQT components are Arithmetic Reasoning, Word Knowledge, Paragraph Comprehension, and Mathematics Knowledge.
} 
the highest grade completed by each given age, and do so between age 16 until age 26. Measuring schooling until grade transitions from age 25 to 26 constitutes a major difference with most of the papers found in the literature (such as Belley and Lochner, 2007) who investigated the determinants of schooling attainments by age 21 (focussing on college participation).

To motivate our approach, it is informative to examine the fraction of the population experiencing a grade progression between age 16 and 25 and for both cohorts (see Figure 1). First, and not surprisingly, the proportion of the population experiencing a grade progression tends to be higher in the 1997 cohort than in the 1979 cohort (except at age 16). Second, it is interesting to note that for the 1997 cohort, the proportion remains between $10 \%$ and $20 \%$ between age 22 and 25 . For the 1979 cohort, the proportion is smaller but remain significant.

As is done in the literature, we use information on family income for each individual at ages 16 and 17, if available, and construct an average income measure. If income is only available for one of the years, the average income is replaced by that income. If no income information is available for these ages, we consider income at earlier ages if available in order to minimize the number of individuals dropped because of missing income. For both cohorts, we express income in year 2000 dollars using the CPI for all urban consumers.

Some of the main characteristics of our samples are found in Table 1 (devoted to summary statistics). First, mean family income grew by about 21 percent (from $\$ 54,155$ to $\$ 65,572$ ). This corresponds to a 1 percent growth rate per year, which matches aggregate measures provided by the Bureau of Labor Statistics. ${ }^{9}$ Other studies, including Kinsler and Pavan (2011), Lovenheim and Reynolds (2011), Castex and Dechter (2014) and Nielsen (2015) report similar family income growth. ${ }^{10}$

As is well known, income dispersion has increased even more over this period. In our sample, the standard deviation of family income increased from $\$ 33,308$ in the 1979 sample to $\$ 58,136$ in the 1997 sample. Not surprisingly, family income is higher than average among college entrants. Finally, schooling attainments have increased at all income quartiles but the largest increase has been observed for those in the third family income quartile (from 13.3 to 14.1 years).

\footnotetext{
${ }^{9}$ According to the Bureau of Labor Statistics (variable MEFAINUSA672N), median household income grew by 20.6 percent between 1980 and 2000 .

${ }^{10}$ Castex and Dexter (2014) report changes in the logarithm of income but their sample data also discloses a growth in real income levels which is comparable to ours.
} 
In a supplementary file appendix, we evaluate the impact of real income on highest grade completed obtained from standard OLS regressions and compare those with estimates measuring differences in schooling by income quartiles.

\section{A Model of Educational Attainments}

To construct our model, we build on the literature on reduced-form models of schooling such as Cameron and Heckman (2001) and Ashworth et al. (2020) and in which intertemporal utilities are represented by linear (in the parameters) functions and in which unobserved heterogeneity plays a key role. Our model uses a reduced-form representation of the grade attainment process but also allows for potential discontinuities.

\subsection{Choice Probabilities}

We assume that the decision process starts at age 16 . The choice variable is denoted $d(a)$, where $d(a)=1$ when an individual decides to invest in an additional grade attainment at age $a$ and where $d(a)=0$ when choosing the alternative option. We denote accumulated schooling by age $a$ as $G(a)$ and accumulated non-school periods as $N(a)$. At each age $a$, every individual therefore chooses between accumulating an additional grade or to involve in other activities. When $d(a)=1$, it follows that $G(a+1)=G(a)+1$.

To avoid the estimation of an excessively large number of parameters, we allow the parameters of the model to vary with age according to 3 different levels. The first level captures the effect of regressors and unobserved factors on progression between 16 and 18. The second one covers age 19 until 21, while the third one deals with transitions from age 22 to 25 .

Given age, we allow grade progression to depend on an indicator denoted $G^{h s}(a)$ equal to 1 when an individual has completed high school and 0 if not. We do so to avoid collinearity problems as grade attainment is correlated with age. It allows us to capture changes in the cost of education when reaching post-high school education.

The school choice probabilities are defined as follows:

$$
\begin{gathered}
\operatorname{Pr}\left(d_{i}(a)=1 \mid Z_{i}(a)\right)=\bigwedge\left\{\beta_{0 i}^{16}+\beta_{Z}^{16} \cdot Z_{i}(a)\right\} \text { for } a=16,17,18 \\
\operatorname{Pr}\left(d_{i}(a)=1 \mid G_{i}^{h s}(a), Z_{i}(a)\right)=\bigwedge\left\{\beta_{0 i}^{19}+\beta_{h s}^{19} \cdot G_{i}^{h s}(a)+\beta_{Z}^{19} \cdot Z_{i}(a)\right\} \text { for } a=19,20,21
\end{gathered}
$$


$\operatorname{Pr}\left(d_{i}(a)=1 \mid G_{i}^{h s}(a), Z_{i}(a)\right)=\bigwedge\left\{\beta_{0 i}^{22}+\beta_{h s}^{22} \cdot G_{i}^{h s}(a)+\beta_{Z}^{22} \cdot Z_{i}(a)\right\}$ for $a \geq 22$

where

$$
\begin{aligned}
& \beta_{0 i}^{19}=\delta_{0}^{19}+\delta_{1}^{19} \cdot \beta_{0 i}^{16} \\
& \beta_{0 i}^{22}=\delta_{0}^{22}+\delta_{1}^{22} \cdot \beta_{0 i}^{16}
\end{aligned}
$$

and where $\delta_{0}^{19}, \delta_{1}^{19}, \delta_{0}^{22}, \delta_{1}^{22}, \beta_{h s}^{19}, \beta_{h s}^{22}, \beta_{Z}^{19}, \beta_{Z}^{22}$ are parameters to be estimated. The vector $Z_{i}(a)$ is equal to $\left\{N_{i}(a), X_{i}\right.$, birthyear, $A F Q T_{i}$, Fam.Income, Fam.Income $\left.{ }^{2}\right\}, \bigwedge($.$) denotes the logistic distribution function, \beta_{0 i}^{16}$ is an unobserved heterogeneity term (defined below) and $\beta_{Z}^{16}$ is a vector of parameter to be estimated. The vector $X_{i}$ contains individual and family characteristics detailed below and birthyear $i$ is a set of binary indicators for the year of birth.

\subsection{Unobserved Heterogeneity and the Initial Condition}

In line with Bajari, Fox and Ryan (2007) and Train (2008), we adopt a fixed mass points approach by choosing grid points covering the entire range of possible values and estimate all associated frequencies (type probabilities) while adapting this approach so to incorporate the endogeneity of initial conditions. To start, we assume $M$ support points. Each type $m$ is endowed with a vector $\left\{\beta_{0 m}^{16}, \beta_{0 m}^{19}, \beta_{0 m}^{22}\right\}$. We impose a positive correlation by forcing both $\delta_{1}^{19}$ and $\delta_{1}^{22}$ to be non-negative.

In an ideal setting, we would access measures of non-cognitive skills for both cohorts and evaluate changes in its effect on grade attainment as we do for AFQT scores. Unobserved heterogeneity would then be interpreted as a residual factor prevailing after conditioning on cognitive and non-cognitive factors.

This solution is however impossible to implement. There exist some noncognitive skill measures in the NLSY but they are only available in the 1979 cohort. Those are the Rotter Locus of Control index and the Rosenberg selfesteem score. The Rotter Locus of Control is designed to measure the extent to which individuals believe they have control over outcomes through selfmotivation or self-determination (internal control) as opposed to the extent that the environment controls their lives (external control). The Rosenberg Self-Esteem Scale is a 10-item scale measuring the self-evaluation that an individual makes. It describes a degree of approval toward oneself. 
To circumvent orthogonality conditions between unobserved heterogeneity and observed characteristics (family income, AFQT scores, and others), and in order to make use of the availability of non-cognitive measures in the 1979 cohort, we proceed as follows.

First, we obtain a predicted Rotter scale (denoted $\hat{L}_{i}$ ) and a predicted Rosenberg scale (denoted $\hat{R}_{i}$ ) by regressing them on all observed characteristics and AFQT scores using the 1979 cohort. We then use the parameters to construct predicted values for both the 1979 and the 1997 cohorts, assuming a stable relationship between the measures and parental background variables. This provides us with a vector of predicted values for each cohort. ${ }^{11}$

We then build a distribution of unobserved heterogeneity incorporating those values. ${ }^{12}$ While it would have been possible to use the actual scores for the 1979 cohort, this would have introduced an asymmetry between cohorts. Instead, we preferred to use predicted scores in both cohorts. To capture both the correlation between unobserved heterogeneity and individual characteristics (including AFQT scores) and the endogeneity of grade attainment by age 16 (the initial condition), the type proportions, $p_{m}($.$) , are$ allowed to depend on the initial grade level, $G(16)$, and on predicted values of the Rotter and the Rosenberg scales $\left(\hat{L}_{i}\right.$ and $\left.\hat{R}_{i}\right)$ respectively. That is,

$$
p_{m}\left(G_{16}, \hat{L}_{i}, \hat{R}_{i}\right)=\frac{\exp \left(\tilde{p}_{m}+\tilde{p}_{m G} \cdot G_{i}(16)+\tilde{p}_{m L} \cdot \hat{L}_{i}+\tilde{p}_{m R} \cdot \hat{R}_{i}\right)}{1+\sum_{j=2}^{M} \exp \left(\tilde{p}_{j}+\tilde{p}_{j G} \cdot G_{i}(16)+\tilde{p}_{j L} \cdot \hat{L}_{i}+\tilde{p}_{j R} \cdot \hat{R}_{i}\right)}
$$

While this approach is based on the maintained assumption that Rotter and the Rosenberg scores are stable across cohort (and that their correlation with characteristics are also stable), the flexibility of the parameters $\tilde{p}_{m L}$ and $\tilde{p}_{m R}$ which can vary across cohorts, allows us to measure variations in the relative importance of unobserved heterogeneity. We can also compare our results with those obtained assuming orthogonality in order to examine to what extent our results are affected by the allowance for correlated effects.

\footnotetext{
${ }^{11}$ The results of those OLS regressions are found in Table S6 in a supplementary file.

${ }^{12} \mathrm{~A}$ more ambitious alternative option (which we follow in a companion paper) would be to make use of the ASVAB measurement components in both cohorts, along with the components of the Rotter index and the Rosenberg index, and estimate the stationary (across cohort) distribution of cognitive and non-cognitive factors while allowing those to depend on observed characteristics.
} 


\subsection{Estimation}

We estimate the model by mixed likelihood techniques. Each individual $i^{\prime} s$ grade attainment progression history is contained in the following vector

$$
\left\{G(16)_{i}, d_{i}(a=16), d_{i}(a=17), \ldots d_{i}(a=25)\right\}
$$

and the likelihood function for observation $i$ is equal to

$L_{i}()=.\sum_{m=1}^{M} p_{m}(.) \cdot \prod_{a=16}^{25}\left(\operatorname{Pr}\left(d_{i a}=1 \mid \text { type } m\right)\right)^{I\left(d_{i a}=1\right)} \cdot\left(\operatorname{Pr}\left(d_{i a}=0 \mid \text { type } m\right)\right)^{I\left(d_{i a}=0\right)}$

where $I($.$) is the identity function. The likelihood of the sample data is$ formed by the product of each individual contribution.

To estimate the model, we defined the heterogeneity distribution over 10 support points ranging from -2.0 to 0.0 with intervals of 0.2 for the 1979 cohort and ranging from -2.5 to -0.5 with intervals of 0.2 for the 1997 cohort. These ranges ensure that probabilities can approach 0 or 1 if needed. As each type probability depends on 4 parameters, we thereby characterize the heterogeneity distribution with 46 parameters (36 for the type probabilities and 10 fixed support points). The distribution of unobserved heterogeneity and the evolution of educational selectivity will be summarized in Section 5. Other specifications will be discussed later in a sub-section devoted to robustness checks.

\section{Changes in the Effects of Family Income and AFQT Scores}

As for most non-linear models, the parameter estimates are not directly informative. For this reason, we focus our presentation of the results on two different statistics illustrating the mechanics of the model and present the parameter estimates in a set of tables (S8-S12) found in a supplementary file. As the model is sequential and allows for the effect of income and AFQT scores to change as individuals age, we first compute marginal effects on the probability of attaining an additional grade level at ages 18, 20 and $22 .{ }^{13}$

Our second set of marginal effects captures the impact of family income and AFQT scores on different measures of schooling attainment at a given

\footnotetext{
${ }^{13} \mathrm{As}$ is normally expected from a reduced-form model incorporating flexible unobserved heterogeneity, it is found to fit the data quite well. The fit is summarized in a table found in a supplementary material file (Table S7).
} 
age (highest grade completed and a college attendance indicator). They are obtained by compounding grade progression probabilities until age 26 and regressing those outcomes on measured family income. With these marginal effects, it is possible to relate our results to those reported in the literature in which observed schooling outcomes are regressed on income and a set of individual and family characteristics.

We present income effects on educational outcomes at different ages (18, $22,25)$ so to allow the age-income effect differential to set in. Schooling attainment measured at age $25-26$ is likely to provide a more reliable indicator of total life-cycle schooling than those at age 22 as a significant proportion of individuals experience grade transitions beyond age 22 .

To obtain the marginal effects, we simulate educational choices between age 16 and 25 for a large number of individuals $(10,000)$ reflecting the unobserved type distribution as well as random shocks. We then compute marginal effects on grade progression probabilities and highest grade completed and use the asymptotic distribution of parameter estimates to evaluate their standard errors.

\subsection{The Effects of Income and AFQT Scores on Grade Pro- gression}

The marginal effects of income and AFQT scores on the probability of obtaining an additional grade are reported in Table 2 . When estimating the model, family income is measured in units of $\$ 10,000$ (the base year is 2000) and AFQT scores are introduced as standardized residuals of a regression of AFQT scores on grade completed when ASVAB tests were administered. Note that our AFQT scores are already adjusted to account for differences across cohorts.

To obtain these effects, we set all observed regressors to their sample average. We evaluate marginal effects at four different levels corresponding to the average income within the first, second, third and fourth income quartiles of each cohort. At each of these points, we compute the effect of an increase of $\$ 10,000$. For the 1979 cohort, the four income levels are $\$ 17,434, \$ 39,487, \$ 60,269$ and $\$ 99,184$, respectively. For the 1997 cohort, they are equal to $\$ 13,937, \$ 46,726, \$ 69,631$ and $\$ 141,855$. Expressed in terms of the standard deviation of the income distribution, a $\$ 10,000$ increase is equivalent to about $33 \%$ of the standard deviation for the 1979 cohort and less (about 17\%) for the 1997 cohort. To provide an overall picture, we also compute them at mean family income. 
For the effects of AFQT scores, we proceed similarly and compute the marginal effect of AFQT's at each income quartile and at mean income. To facilitate comparability with income effects, we measure the impact of a change equal to $1 / 3$ of the standard deviation of AFQT's. The marginal effects of income and AFQT scores on grade transition are averaged over types.

The results have been obtained for the model specification with correlated effects but also from a specification in which type probabilities depend only on initial grade level. Because the main results are practically identical and all the main conclusions persist when the distribution of types depends only on initial grade, we comment only on those obtained with correlated effects. Estimates obtained with alternative specifications are available in a supplementary appendix.

\subsubsection{Income Effects}

There are 4 main features about grade progression income effects to retain from Table 2. First, and aside from transitions taking place beyond age 21, family income effects on grade transitions have a concave shape as they tend to be generally higher at low income levels than at higher ones. This is true for both cohorts although concavity is much less pronounced in the 1997 cohort.

A second finding is that income effects on pre-college transitions (from age 16 to 18) are as strong as they are on transitions taking place from age 19 onwards. For instance, when evaluated at mean income, the 1979 cohort income effect on age 20 transitions (equal to 0.012 ) is practically identical to that measured at age 18 (which is equal to 0.010). For the more recent cohort, the average income effect at age 18 (averaging 0.007 ) actually exceeds the age 20 income effect (which is equal to 0.004) but these are so small that their difference may not raise substantial interest.

Keeping in mind that the vast majority of grade progression transitions takes place before age 22, the third and most important finding remains the overwhelming evidence that the effects of family income on grade progression have decreased between the early 1980's and the early 2000's. When comparing marginal effects measured at 18 and 20 at each specific income quartile obtained for the 1979 cohort with those obtained for the 1997 cohort, we observe that grade progression probabilities decrease by numbers ranging between 0.01 (at low income) to 0.005 (at high income). When measured at average income, these estimates translate into a $30 \%$ decrease 
in pre-college grade progression income effects and practically a $80 \%$ decrease for early college transitions. The effects of income at age 22 have also decreased by about 0.005 to approach 0 .

As all these estimates measure the impact of income on a single grade transition probability, compounding those effects over early adulthood may be sufficient to generate even more significant differences in income effects when considering total schooling by age 22 or beyond. We shall return to this point below.

Finally, a fourth finding is that although we already noted the growing frequencies of belated grade progression between the 1980's and the early 2000 's, those transitions appear to be disconnected from family income. While we also note a decrease in income effects between the early 1980's and the early 2000's, their low magnitude obviate the need for further comments on their evolution.

\subsubsection{The Effects of AFQT Scores}

With respect to grade progression effects of AFQT scores, there are 3 main points to be made. First, AFQT scores are the most important determinant of grade progression and, in particular, their marginal effects remain significant in the 1997 cohort. Notwithstanding that the effects of age and education have been removed from AFQT measures, a 1/3 standard deviation difference in the AFQT residual (evaluated at mean income) changes grade progression probabilities by 0.022 at age 18 , by 0.050 at age 20 , and by 0.035 at age 22 , in the early 1980 's. As a comparison, increments of $\$ 22,000, \$ 41,000$ and $\$ 70,000$ would have been needed to generate a similar change in grade progression. In the early 2000's, the AFQT marginal effect on early grade transitions, equal to 0.021 , was equivalent to a $\$ 30,000$ increase while the effect on transitions between 19 and 21, equal to 0.016, was worth about $\$ 40,000$. The AFQT effect on belated progression (at age 22), equal to 0.008 , cannot be evaluated in dollars as income does not matter for those transitions.

For the 1979 cohort, a second finding is that AFQT scores had stronger effects on early college transitions (at age 20) than on both high school and belated college transitions. However, in the early 2000's, the effects of AFQT's appear to decrease with age. For instance, AFQT's have practically no impact on age 22 transitions. In the older cohort, AFQT had still strong effects on belated college transitions.

Third and foremost, and across cohorts, the effects of AFQT scores on 
grade transitions have decreased between the 1980's and the early 2000's. The only exception has been pre-college transitions (from 16 to 18) for which AFQT scores effects have remained constant. For the rest, they have been divided by more than 3 . To illustrate this, and when evaluated at mean income level, a $1 / 3$ standard deviation increase in AFQT raised early grade progression by 0.022 in the 1979 cohort and by 0.021 in the 1997 cohort. However, for transitions taking place at age 20, the same change in net AFQT raised grade progression by 0.050 in the 1979 cohort but by only 0.016 in the 1997 cohort. For belated college transitions, the AFQT effects dropped from 0.035 to 0.008 . This indicates that differences in cognitive skills, to the extent that those are measured by AFQT scores, have become less important for college transitions but remained an important determinant of grade progression until age 18 .

\subsection{The Effects of Income and AFQT Scores on Educational Outcomes}

After documenting the effects of income on grade progression probabilities, we now turn to marginal effects of income on educational outcomes as recorded by a given age. As noted earlier, much of the existing literature has focussed on outcomes measured around age 21-22 and ignored age-dependent income effects. To compute them, we proceed similarly and use simulated outcomes at ages 18,20,22 and 25. The results, found in Table 3, summarize income and AFQT effects on highest grade completed and also on a college attendance indicator equal to 1 if an individual has ever attended college. To avoid repetitive comparisons, we report the effects evaluated at mean income.

\subsubsection{Income Effects}

Aside from the relatively less important drop in income effects on grade attainment measured at age 18, income effects on schooling measured at ages 20, 22 and 25, have lost more than $50 \%$ of their magnitude over time.

When education outcomes are summarized by the college attendance indicator, the decrease is even more spectacular. In the 1979 cohort, a $\$ 10,000$ differential raised the population proportion attending college by $1.4 \%$ but by the early 2000 's, it did so by only $0.3 \%$.

As a result, a $\$ 300,000$ differential in family income generated more than 2 years of education in the early 1980's, but only one year in the early 
2000's. Put differently, a $\$ 70,000$ family income differential raised college participation by 10 percentage points in the early 1980's. In the early 2000 's, a $\$ 330,000$ income differential had the same impact on college participation.

As already noted when we analyzed grade progression probabilities, this general finding goes against conventional wisdom as economists are often tempted to assimilate the documented increase in educational differences between high and low income quartiles (which often ignores belated college completion) to an increase in the effect of real income. Our findings suggest that it is far from being the case.

\subsubsection{AFQT Scores}

As noted earlier, a distinction must be made between pre-college transitions and transitions taking place beyond age 18. In line with the evolution of grade progression probability income effects, the effects of AFQT scores on grade attainments measured at ages 20,22 and 25 have all decreased substantially between the 1980's and the early 2000's. This is the case for all income quartiles and also for mean income. More precisely, an increase of $1 / 3$ standard deviation in AFQT residuals in the 1980's increased grade attainment by 0.162 year at age 20 , by 0.254 at age 22 and by 0.324 by age 25. In the early 2000's, the corresponding marginal effects had dropped to 0.084 (at age 20), 0.116 (at age 22) and 0.143 (at age 25). All in all, the effects of AFQT on schooling attainments measured at any point between age 19 and 25 have been reduced by $50 \%$ between the early 1980's and the early 2000's.

As for family income, the drop in AFQT score effects is more spectacular when stated in terms of college attendance. In the early 1980's, a one third standard deviation increase raised college attendance by 6.4 percentage points. In the early 2000 's, it did so by only 1.5 percentage points.

\subsection{Summary}

We now summarize the main results. As indicated by their standard errors, the effects of income and AFQT are as precisely estimated in both cohorts. While income effects are usually positive and significant in the 1979 cohort, they are often not significantly different from 0 in the 1997 cohort. Even if their differences across cohorts are not always statistically significant, there is virtually no age level and no income level at which income effects have increased over time. 
For AFQT's, the results are similar with the exception that their marginal effects remain significant in the 1997 cohort. Indeed, in most cases, the difference between 1997 and 1979 effects is significantly different from 0, and the evidence in favor of a decrease in importance of AFQT's is overwhelming.

\subsection{Robustness}

To verify the robustness of our results, we implemented two different versions of the model. First, and in order to check to what extent our main results are driven by the correlation between unobserved abilities and the projection of non-cognitive skill measures onto family characteristics, we estimate a version that does not use non-cognitive measures and thereby assumes that the distribution of types depends on initial grade only.

Second, and in order to evaluate the potential sensitivity of our results to the presence of very high and very low income, we also re-estimated the models after removing the top $1 \%$ and the bottom $1 \%$ income levels. This may be justified by the potentially higher likelihood of mis-measurement of income at extreme levels.

In a supplementary appendix (Table S4 and Table S5), we report results that document clearly that our main results are robust to an alternative specification of the distribution of unobserved heterogeneity and that they are not explained by the behavior of individuals endowed with either very low or very high family income levels.

\subsection{Comparison with a Relative Income Approach}

The existing literature has focussed mostly on documenting the evolution of education inequality in conjunction with income inequality and, for this reason, has studied the evolution of average education outcomes at different income quantiles.

Although individual decisions are most likely not guided by relative income position but by real income, we estimated a version of our model specification with non-cognitive measures after replacing real income by a set of quartile indicators in order to obtain estimates of the evolution of educational differences which would be more comparable with those reported in the literature.

When estimating the model, we use the lowest quartile as the reference group and report marginal effects as the difference in schooling attainments between a given quartile and the first one. These educational differentials 
are partly affected by the evolution of real income effects and by changes in family income distribution. The estimates are presented in Table 4. We comment on grade attainment and on the proportion of college attendance at age 25 .

Although reported educational differences may not be interpreted as emerging solely from changes in real income effects, the results are in line with the decreasing trend documented earlier. They show that there was a reasonably steep relative income gradient in the 1979 cohort for college attendance but that it has almost disappeared for the 1997 cohort. Similarly, the attendance probability differential across quartiles in the 1979 cohort turned out to be substantially larger than for the 1997 cohort.

Either in terms of grade attainment or college completion, educational differences between those in quartiles 2, 3 and 4 on one hand and those in quartile 1 on the other hand, have decreased. This is particularly noticeable when considering the differentials between the second and first quartiles which have practically disappeared.

To some extent, these results further illustrate the robustness of our general finding of weaker income effects on college attendance and grade completion for the 1997 cohort. They indicate that the decrease in the effect of real income on higher education has been sufficiently strong to counteract the effect of the increase in income dispersion and thereby prevent an increasing education gap between high and low family income families, after conditioning on both observed and unobserved characteristics.

\section{Changes in Educational Selection and Unobserved Heterogeneity}

In order to comprehend the sources of changes in marginal effects of family income and AFQT scores, it is necessary to evaluate the relative importance of unobserved heterogeneity within each cohort and to quantify its evolution. This is a crucial step toward understanding the role played by dynamic selection.

\subsection{The Importance of Unobserved Heterogeneity}

The distribution of unobserved heterogeneity is summarized in Table 5. In both cohorts, we find evidence of 4 distinct types. In the 1979 cohort, more than half of the population is endowed with an intercept of -2.0 while about 
a quarter has -0.4. Dispersion is also high in the 1997 cohort as we find an intercept of -2.5 for $10 \%,-1.1$ for $26 \%$, and a total of $65 \%$ at -0.7 or -0.5 .

There are 3 specific questions that we need to answer. Which observed characteristics are more highly correlated with unobserved heterogeneity? Has the dependence of the distribution of unobserved heterogeneity on observed characteristics changed ? What happened to the distribution of unobserved heterogeneity across cohort and to what extent has the relative importance of unobserved heterogeneity changed between the early 1980's and the early 2000's?

To answer these questions, we simulate the distribution of unobserved heterogeneity using the parameters measuring the impact of initial grade and non-cognitive measures on type probabilities. We then regress realized unobserved heterogeneity on each individual characteristic one-by-one and then on all characteristics. In Table 6, we report the R-squared of each regression in column 1 (1979 cohort) and in column 2 (1997 cohort). We also ran separate regressions of simulated schooling (as measured by age 25) on individual characteristics as well as on unobserved heterogeneity. This allows us to obtain a ranking of the relative importance of each determinant, and in particular, to see which characteristics have become more or less important over time. Those results are in column 3 (1979 cohort) and column 4 (1997 cohort).

There are three elements to retain from the first two columns of Table 6 on the decomposition of the distribution of unobserved heterogeneity. First, the R-squared of the regressions incorporating income and AFQT scores are both equal to 0.075 in the 1979 cohort. While these indicate relatively low correlations, AFQT's and income are the characteristics with the highest level of correlation with unobserved types. The intact family indicator is also correlated with unobserved heterogeneity.

Second, in the 1997 cohort, AFQT is the variable with the highest Rsquared, 0.058, but the movement in family income R-squared (from 0.075 to 0.027) indicates that income has become less correlated with the unobserved factor.

Third, and when taken globally, our estimates indicate that the overall correlation between unobserved heterogeneity and family characteristics has decreased.

Turning to the decomposition of educational outcomes, we note that among observed individual and family characteristics, only the "Intact Family" indicator, has become notably more important over the period considered. It is however impossible to say if this relationship is causal or just 
explained by a change in composition of the sub-population experiencing family separations. It is also interesting to note that Blacks also tend to be more educated, after conditioning on all characteristics. This finding is not incoherent with the generally lower proportion of Blacks attending college found in many US data sets. However, mother's education remains the best predictor.

In line with our main results, a second notable finding is the drop in both AFQT R-squared, which went from 0.343 in the 1979 cohort to 0.262 in the 1997 cohort, and family income, which dropped from 0.162 to 0.076 . Despite that, AFQT score remains the most important predictor of educational attainments in the early 2000's before mother's education.

The third and most striking finding, is the increase in the relative importance of unobserved heterogeneity. In the early 1980's, unobserved heterogeneity accounted for about $50 \%$ of schooling attainment. By the early 2000's, unobserved heterogeneity has become by far the most important determinant of education and accounts for almost $75 \%$ of the explained variations in schooling. It has therefore become more important than the entire set of individual and family characteristics.

Finally, OLS estimates reported in Table S6 (in a supplementary file) indicate that both the Rotter scale and the Rosenberg scale are weakly correlated with observed regressors as indicated by the R-squared of the regressions used to generate their predicted values, and equal to 0.06 and 0.08 respectively. AFQT score is the characteristic that has the highest correlation with both measures. The effect of income on the Rotter index is very weak and its effect on the Rosenberg self-esteem measure is insignificant.

\subsection{Impact of Ignoring Unobserved Heterogeneity}

Evaluating the implication of ignoring unobserved taste for schooling is also a crucial issue to comprehend our main results. The consequences of ignoring dynamic selection on estimates of the effect of income on educational outcomes are however difficult to anticipate as our model allows for agedifferentiated effects of unobserved heterogeneity and observed characteristics on schooling. If there are going to be consequences of ignoring dynamic selection on income effects, we expect them to be more important on the recent cohort since we found unobserved heterogeneity to be relatively more important for it. ${ }^{14}$

\footnotetext{
${ }^{14}$ In some specific econometric settings, such as Proportional Hazards models in which unobserved heterogeneity hits the hazard rate multiplicatively, the impact of ignoring
} 
To evaluate the impact of ignoring dynamic selection, we compare marginal effects of income and AFQT scores obtained with and without unobserved heterogeneity. To simplify our analysis, we compare marginal income effects obtained at the average income level. Those are found in Table 7 . To ease comparison, we also reproduce the estimates of Table 2 (our most general model) in the bottom panel of Table 7 .

The impact of ignoring unobserved heterogeneity comes out relatively clearly. First, and as normally expected, income effects on early grade progression are much less affected than later ones as the effect of dynamic selection sets in more clearly as age progresses. In the 1979 cohort, the average income effect on grade progression probabilities are multiplied by 2, going from 0.012 to 0.023 at age 20, and from 0.005 to 0.009 at age 22 . In the 1997 cohort, income effects are even more inflated. For instance, income effects at age 20, equal to 0.004 with unobserved heterogeneity, are multiplied by 4 to reach 0.016 . At age 22 , the average income effect ignoring heterogeneity is positive (0.006) while that obtained when incorporating is equal to 0 at 4 decimals.

When translated into grade attainment income effects, ignoring heterogeneity inflates income effects in both cohorts but in different proportions. It multiplies them by 2 in the 1979 cohort and by 3 to 4 in the 1997 cohort. At age 25, ignoring heterogeneity moves income effects on grade attainment from 0.073 year to 0.147 year and raised college participation income effects from 1.4 to 3.8 percentage points in the 1979 cohort. In the 1997 cohort, it moves grade attainment income effects from 0.027 year to 0.115 year and inflates college participation income effects from 0.3 to 2.3 percentage points.

Thus, not accounting for dynamic selection inflates income effects on both grade progression probabilities and schooling attainments within each cohort. Because unobserved heterogeneity is found to be relatively more important in the early 2000's, the income effect inflation is even more serious for the 1997 cohort. While ignoring unobserved heterogeneity would still reveal decreasing income effects, it would do so from inaccurate estimates. Moreover, ignoring dynamic selection would hide the fact that income effects have practically vanished. Our results are in line with Ashworth et al. (2020) who report the need to account for dynamic selection (changes in composition) when analyzing changes in returns to education for the 1979

dynamic selection may be derived analytically. See Lancaster, 1990, for a formal analysis in a continuous duration setting, and Cameron and Heckman (1998) for a discussion within a discrete duration setting. 
and 1997 cohorts of the NLSY.

Finally, and upon comparing AFQT effects with and without heterogeneity, the conclusion is similar. In both cohorts, ignoring unobserved heterogeneity drives AFQT marginal effects at much higher levels than those obtained when unobserved heterogeneity is accounted for.

\section{Interpretation and Conclusion}

Our main findings are in accord with the evolution of college attendance in the US. The number of individuals graduating with a Bachelor's degree has fluctuated between 1.5 and 3 millions per year in the past 20 years and is larger than what was observed in the early 1980's. When coupled with the increased capacity at lower quality and lower tuition institutions, this may explain the decreasing impact of real family income and AFQT score on educational attainment and the emergence of a new form of educational selectivity reserving an increasing role to non-cognitive abilities and/or preferences.

The effect of family income on education inequality is however far from being a closed research topic. Our results raise questions that could open avenues for future research. One would be to evaluate if those coming from lower income families have been forced to supply labor while in school in order to finance their education. If so, it would also be interesting to know if those using more labor supply intensive trajectories have been penalized for doing so. Addressing this issue would require to model simultaneous school attendance and labor supply margins.

Our paper has focussed on the US, which is known to provide high incentives to education but relatively low investment levels for disadvantaged children. It would be interesting to see how income effects have evolved in countries where a higher share of public expenditures goes to skill investment among the disadvantaged and where university tuitions are lower. ${ }^{15}$

Finally, it would be highly relevant to investigate the factors lying behind the increase in relative importance of unobserved heterogeneity. These are fundamental issues that we are currently examining in ongoing research.

\footnotetext{
${ }^{15}$ Landerso and Heckman (2017) study differences in intergenerational mobility between Denmak and the US and conclude that despite differences in public policies, they disclose a similar correlation between family resources and educational attainment.
} 


\section{References}

[1] Abel, Jaison. R. and Richard Deitz (2014), Do the Benefits of College Still Outweigh the Costs?, Current Issues in Economics and Finance, New York

[2] Abbot, Brant, Giovanni Gallipoli, Costas Meghir, and Giovanni L. Violante (2016) Education Policy and Intergenerational Transfers in Equilibrium, NBER Working Paper No. w18782,

[3] Altonji, Joseph G., Prashant Bharadwaj, and Fabian Lange (2012), Changes in the Characteristics of American Youth: Implications for Adult Outcomes, Journal of Labor Economics, 30, 783-828.

[4] Ashworth, Jared, V. Joseph Hotz, Arnaud Maurel, and Tyler Ransom (2020), Changes across Cohorts in Wage Returns to Schooling and Early Work Experiences, Working paper, Duke University.

[5] Bajari, Patrick, Fox, Jeremy and Steve Ryan (2007) "Linear Regression Estimation of Discrete Choice Models with Nonparametric Distributions of Random Coefficients" American Economic Review. April 2007, Vol. 97, No. 2: Pages 459-463

[6] Bailey, Martha J. and Susan M. Dynarski (2011), Inequality in postsecondary education, in Whither Opportunity?: Rising Inequality, Schools, and Children's Life Chances, Greg J. Duncan and Richard J. Murnane, eds. (New York: Russell Sage), 117-132.

[7] Beaudry, Paul, David A. Green, and Benjamin M. Sand (2013), The Great Reversal in the Demand for Skill and Cognitive Tasks, NBER Working Paper No. w18901.

[8] Belley, Philippe and Lance Lochner (2007), The Changing Role of Family Income and Ability in Determining Educational Achievement, Journal of Human Capital, 1, 37-89.

[9] Belley, Philippe, Marc Frenette, and Lance Lochner (2014), Postsecondary Attendance by Parental Income in the U.S. and Canada: Do Financial Aid Policies Explain the Differences?, Canadian Journal of Economics, 47, 664-696.

[11] Bound, John, Michael Lovenheim, and Sara Turner (2010): "Why have college completion rates declined? An analysis of changing student preparation and collegiate resources," American Economic Journal: Applied Economics, 2(3), 129-57.

[12] Cameron Stephen V. and James J. Heckman (1998), Life Cycle Schooling and Dynamic Selection Bias: Models and Evidence for Five Cohorts of American Males, Journal of Political Economy, 106, 262-333. 
[13] Cameron Stephen V. and James J. Heckman (2001), The Dynamics of Educational Attainment for Black, Hispanic, and White Males, Journal of Political Economy, 109, 455-499.

[14] Cameron Stephen V. and Christopher Taber (2004), Estimation of Educational Borrowing Constraints using Returns to Schooling, Journal of Political Economy, 112, 132-182.

[15] Carneiro Pedro and James .J. Heckman (2002) The Evidence on Credit Constraints in Post-Secondary Schooling, Economic Journal, 112, 705-734.

[16] Castex, Gonzalo and Evgenia K. Dechter (2014), The Changing Role of Education and Ability in Wage Determination, Journal of Labor Economics, 32, 685-710.

[17] Chetty, Raj, Nathaniel Hendren, Patrick Kline, Emmanuel Saez, and Nicholas Turner (2014), Is the United States Still a Land of Opportunity? Recent Trends in Intergenerational Mobility, American Economic Review 104, 141-147.

[18] Deming, David J. (2017) The Growing Importance of Social Skills in the Labor Market. Quarterly Journal of Economics, 132(4): 1593-1640.

[19] Dynarski, Susan M. and Judith Scott-Clayton (2013), Financial Aid Policy: Lessons from Research, Future of Children, 23, 67-91.

[20] Hai, Rong and James J. Heckman (2017), Inequality in Human Capital and Endogenous Credit Constraints, Review of Economic Dynamics, 25, 4-36.

[21] Hoxby, Caroline (2009), The Changing Selectivity of American Colleges, Journal of Economic Perspective, 23, 95-118.

[22] Keane, Michael P. and Kenneth I. Wolpin (1997), The Career Decisions of Young Men, Journal of Political Economy, 105, 473-522.

[23] Kinsler, Josh and Ronni Pavan (2011), Family Income and Higher Education Choices: The Importance of Accounting for College Quality, Journal of Human Capital, 5, 453-477.

[24] Lancaster, Tony (1990), The Econometric Analysis of Transition Data, Cambridge University Press

[25] Landerso, Rasmus and James J. Heckman (2017) The Scandinavian Fantasy: The Sources of Intergenerational Mobility in Denmark and the US, Scandinavian Journal. of Economics 119(1), 178-230, DOI: 10.1111/sjoe.12219

[26] Lochner, Lance J. and A. Monge-Naranjo (2011), The nature of credit constraints and human capital, American Economic Review 101(6), $2487-2529$. 
[27] Lovenheim, Michael and C. Lockwood Reynolds (2007), Changes in Postsecondary Choices by Ability and Income: Evidence from the National Longitudinal Surveys of Youth, Journal of Human Capital, 5, 70-109.

[28] Lovenheim, Michael F. and C. Lockwood Reynolds (2011), The Effect of Housing Wealth on College Choice: Evidence from the Housing Boom, Journal of Human Resources 48, 1-35.

[29] Nielsen, Eric R. (2015), The Income-Achievement Gap and Adult Outcome Inequality, Finance and Economics Discussion Series 2015-041. Washington: Board of Governors of the Federal Reserve System.

[30] Train, Kenneth (2008) EM Algorithms for nonparametric estimation of mixing distributions, Journal of Choice Modelling Vol. 1, Issue 1, Pages 40-69. 
Table 1: Summary Statistics in 1979 and 1997

\begin{tabular}{|c|c|c|}
\hline & 1979 cohort & 1997 cohort \\
\hline & \multicolumn{2}{|c|}{ Educational Attainment } \\
\hline Highest grade completed & 13.1 & 13.6 \\
\hline Proportion attended college & 0.455 & 0.579 \\
\hline \multirow[t]{2}{*}{ Proportion graduated from college } & 0.218 & 0.306 \\
\hline & \multicolumn{2}{|c|}{ Parental Income } \\
\hline Average & $\$ 54,155$ & $\$ 65,572$ \\
\hline Std dev & $\$ 33,308$ & $\$ 58,136$ \\
\hline Average among college attendants & $\$ 65,319$ & $\$ 77,974$ \\
\hline \multicolumn{3}{|c|}{ Highest grade completed by income quartile } \\
\hline Quartile 1 & 12.0 & 12.4 \\
\hline Quartile 2 & 12.8 & 13.1 \\
\hline Quartile 3 & 13.3 & 14.1 \\
\hline \multirow[t]{2}{*}{ Quartile 4} & 14.2 & 14.7 \\
\hline & \multicolumn{2}{|c|}{ AFQT } \\
\hline Average & 169 & 170.8 \\
\hline Std dev & 30.2 & 30 \\
\hline \multirow[t]{2}{*}{ Average among college attendants } & 185.8 & 182.2 \\
\hline & \multicolumn{2}{|c|}{ Other characteristics } \\
\hline Male & 0.494 & 0.499 \\
\hline Mother's education & 11.7 & 13.2 \\
\hline Intact Family & 0.788 & 0.581 \\
\hline Rural & 0.238 & 0.264 \\
\hline Number of Siblings & 3.1 & 2.3 \\
\hline Black & 0.115 & 0.135 \\
\hline Hispanics & 0.078 & 0.107 \\
\hline Mother's age at birth & 26.3 & 25.8 \\
\hline Sample size & 2,151 & 2,651 \\
\hline
\end{tabular}

Note:

1979 income: \$28,886 (25\%); \$50,163 (50\%); \$71,210 (75\%)

1997 income: \$29,623 (25\%); \$53,010 (50\%); \$82,285 (75\%)

Attended college $=1$ if completed grade 13 or more

Graduated college $=1$ if completed grade 16 or more 
Table 2: Marginal Effects of Family Income and AFQT scores on Grade Transition Probabilities

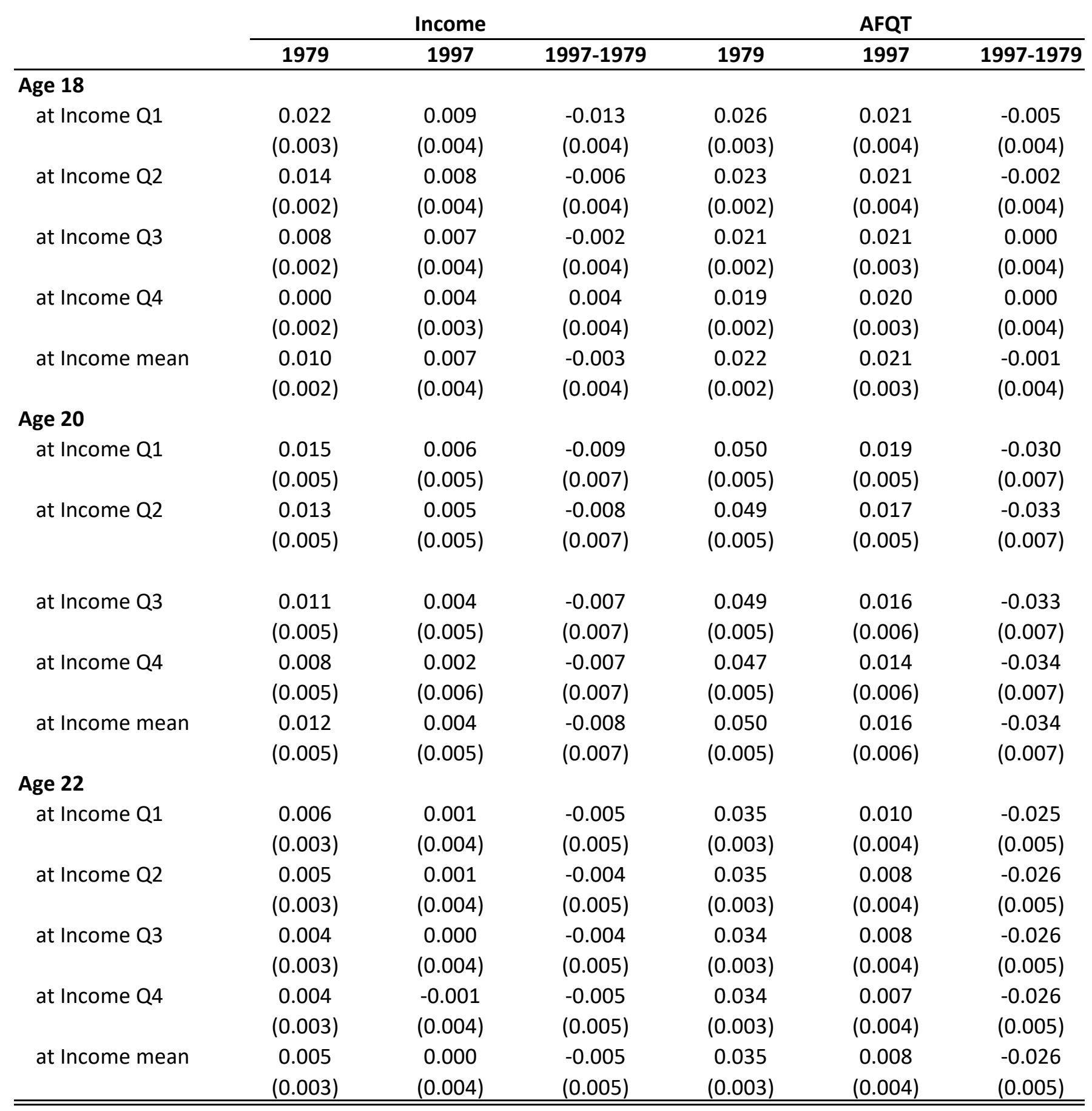

Note: Standard errors in parentheses. 
Table 3: Marginal Effects of Family Income and AFQT scores on Educational Attainment

\begin{tabular}{lcccccc} 
& \multicolumn{3}{c}{ Income } & \multicolumn{3}{c}{ AFQT } \\
\cline { 2 - 7 } & $\mathbf{1 9 7 9}$ & $\mathbf{1 9 9 7}$ & $\mathbf{1 9 9 7 - 1 9 7 9}$ & $\mathbf{1 9 7 9}$ & $\mathbf{1 9 9 7}$ & $\mathbf{1 9 9 7 - 1 9 7 9}$ \\
\hline Highest Grade Completed & & & & & & \\
Age 18 & 0.021 & 0.017 & -0.004 & 0.042 & 0.053 & 0.011 \\
& $(0.004)$ & $(0.010)$ & $(0.011)$ & $(0.004)$ & $(0.010)$ & $(0.011)$ \\
Age 20 & 0.049 & 0.022 & -0.027 & 0.162 & 0.084 & -0.077 \\
& $(0.014)$ & $(0.021)$ & $(0.025)$ & $(0.014)$ & $(0.021)$ & $(0.025)$ \\
Age 22 & 0.065 & 0.027 & -0.038 & 0.254 & 0.116 & -0.138 \\
& $(0.022)$ & $(0.030)$ & $(0.037)$ & $(0.022)$ & $(0.030)$ & $(0.037)$ \\
Age 25 & 0.073 & 0.027 & -0.046 & 0.324 & 0.143 & -0.181 \\
& $(0.025)$ & $(0.040)$ & $(0.047)$ & $(0.026)$ & $(0.040)$ & $(0.047)$ \\
College Attendance & & & & & & \\
Age 25 & 0.014 & 0.003 & -0.011 & 0.064 & 0.015 & -0.049 \\
& $(0.007)$ & $(0.007)$ & $(0.010)$ & $(0.007)$ & $(0.007)$ & $(0.010)$ \\
\hline \hline
\end{tabular}


Table 4: Marginal Effects of Family Income and AFQT scores on Educational Attainment - Relative Income

\begin{tabular}{llllll}
\multicolumn{3}{c}{ Income } & \multicolumn{3}{c}{ AFQT } \\
\hline 1979 & 1997 & $1997-1979$ & 1979 & 1997 & $1997-1979$ \\
\hline \multicolumn{3}{c}{ Income Quartile 2 vs Income Quartile 1 } \\
\hline
\end{tabular}

\begin{tabular}{|c|c|c|c|c|c|c|}
\hline \multicolumn{7}{|c|}{ Grade Transition Probability } \\
\hline Age 18 & $0.026^{*}$ & 0.000 & $-0.026^{*}$ & $0.020 *$ & $0.020^{*}$ & -0.0001 \\
\hline Age 20 & $0.032^{*}$ & -0.001 & $-0.032 *$ & $0.051^{*}$ & $0.019 *$ & $-0.031^{*}$ \\
\hline Age 22 & $0.016^{*}$ & -0.004 & $-0.020^{*}$ & $0.039 *$ & 0.007 & $-0.032^{*}$ \\
\hline \multicolumn{7}{|c|}{ Highest Grade Completed } \\
\hline Age 18 & $0.036^{*}$ & -0.001 & $-0.037^{*}$ & $0.018^{*}$ & $0.056^{*}$ & $0.038^{*}$ \\
\hline Age 20 & $0.131 *$ & -0.003 & $-0.133^{*}$ & $0.171^{*}$ & $0.095^{*}$ & $-0.076 *$ \\
\hline Age 22 & $0.193^{*}$ & -0.012 & $-0.205^{*}$ & $0.305^{*}$ & $0.130^{*}$ & $-0.175^{*}$ \\
\hline Age 25 & $0.223 *$ & -0.035 & $-0.258 *$ & $0.399 *$ & $0.163^{*}$ & $-0.236 *$ \\
\hline \multicolumn{7}{|c|}{ College Attendance } \\
\hline \multirow[t]{2}{*}{ Age 25} & $0.058^{*}$ & -0.002 & $-0.060 *$ & $0.093^{*}$ & $0.016^{*}$ & $-0.077^{*}$ \\
\hline & \multicolumn{6}{|c|}{ Income Quartile 3 vs Income Quartile 1} \\
\hline \multicolumn{7}{|c|}{ Grade Transition Probability } \\
\hline Age 18 & $0.046^{*}$ & $0.050^{*}$ & 0.004 & $0.019 *$ & $0.019 *$ & 0.001 \\
\hline Age 20 & $0.046 *$ & $0.022 *$ & $-0.024 *$ & $0.049 *$ & $0.019 *$ & $-0.030 *$ \\
\hline Age 22 & -0.002 & 0.002 & 0.004 & $0.037^{*}$ & 0.006 & $-0.030 *$ \\
\hline \multicolumn{7}{|c|}{ Highest Grade Completed } \\
\hline Age 18 & $0.054^{*}$ & $0.141^{*}$ & $0.086^{*}$ & $0.013^{*}$ & $0.055^{*}$ & $0.043^{*}$ \\
\hline Age 20 & $0.192 *$ & $0.185^{*}$ & -0.006 & $0.159 *$ & $0.092^{*}$ & $-0.067 *$ \\
\hline Age 22 & $0.260 *$ & $0.214^{*}$ & -0.046 & $0.289 *$ & $0.126^{*}$ & $-0.163 *$ \\
\hline Age 25 & $0.254^{*}$ & $0.220 *$ & -0.034 & $0.365^{*}$ & $0.157^{*}$ & $-0.208 *$ \\
\hline \multicolumn{7}{|c|}{ College Attendance } \\
\hline \multirow[t]{2}{*}{ Age 25} & $0.070^{*}$ & $0.018^{*}$ & $-0.053^{*}$ & $0.093^{*}$ & $0.013^{*}$ & $-0.080^{*}$ \\
\hline & \multicolumn{6}{|c|}{ Income Quartile 4 vs Income Quartile 1} \\
\hline \multicolumn{7}{|c|}{ Grade Transition Probability } \\
\hline Age 18 & $0.063 *$ & $0.041^{*}$ & $-0.022 *$ & $0.017^{*}$ & $0.020^{*}$ & 0.003 \\
\hline Age 20 & $0.111^{*}$ & $0.040^{*}$ & $-0.072 *$ & $0.047^{*}$ & $0.019 *$ & $-0.029 *$ \\
\hline Age 22 & $0.038 *$ & -0.004 & $-0.042 *$ & $0.038 *$ & 0.006 & $-0.033^{*}$ \\
\hline \multicolumn{7}{|c|}{ Highest Grade Completed } \\
\hline Age 18 & $0.065^{*}$ & $0.114^{*}$ & $0.049 *$ & $0.010 *$ & $0.056^{*}$ & $0.046^{*}$ \\
\hline Age 20 & $0.401^{*}$ & $0.192 *$ & $-0.209 *$ & $0.147^{*}$ & $0.091^{*}$ & $-0.056^{*}$ \\
\hline Age 22 & $0.636 *$ & $0.230^{*}$ & $-0.407 *$ & $0.287^{*}$ & $0.117^{*}$ & $-0.170 *$ \\
\hline Age 25 & $0.713^{*}$ & $0.201^{*}$ & $-0.512 *$ & $0.377^{*}$ & $0.142^{*}$ & $-0.235^{*}$ \\
\hline \multicolumn{7}{|c|}{ College Attendance } \\
\hline Age 25 & $0.190 *$ & $0.027^{*}$ & $-0.163 *$ & $0.077^{*}$ & $0.013^{*}$ & $-0.064 *$ \\
\hline
\end{tabular}

Note: ${ }^{*}$ signifies statistical significance at the 5 percent level. 
Table 5: Type Proportions and Location Parameters

\begin{tabular}{ccccc} 
& \multicolumn{2}{c}{1979} & & \multicolumn{2}{c}{1997} \\
\cline { 2 - 5 } Type & Location & Proportion & Location & Proportion \\
\hline 1 & -2.0 & 0.515 & -2.5 & 0.097 \\
2 & -1.8 & 0.000 & -2.3 & 0.000 \\
3 & -1.6 & 0.000 & -2.1 & 0.000 \\
4 & -1.4 & 0.001 & -1.9 & 0.000 \\
5 & -1.2 & 0.054 & -1.7 & 0.000 \\
6 & -0.8 & 0.186 & -1.3 & 0.000 \\
7 & -0.6 & 0.000 & -1.1 & 0.257 \\
8 & -0.4 & 0.242 & -0.9 & 0.000 \\
9 & -0.2 & 0.000 & -0.7 & 0.601 \\
10 & 0.0 & 0.001 & -0.5 & 0.045 \\
\hline \hline
\end{tabular}


Table 6: R-squares from Regressions of Type-specific Location Parameter and Highest Grade Completed

\begin{tabular}{lcccc} 
& \multicolumn{2}{c}{ Location } & \multicolumn{2}{c}{ Highest Grade Completed } \\
\cline { 2 - 5 } & $\mathbf{1 9 7 9}$ & $\mathbf{1 9 9 7}$ & $\mathbf{1 9 7 9}$ & $\mathbf{1 9 9 7}$ \\
\hline Mother's education & 0.016 & 0.028 & 0.185 & 0.125 \\
Intact Family & 0.041 & 0.033 & 0.027 & 0.088 \\
Rural & 0.003 & 0.000 & 0.002 & 0.000 \\
Number of siblings & 0.005 & 0.004 & 0.060 & 0.011 \\
Black & 0.052 & 0.003 & 0.014 & 0.006 \\
Hispanic & 0.005 & 0.001 & 0.022 & 0.010 \\
Mother's age at birth & 0.006 & 0.009 & 0.017 & 0.050 \\
Male & 0.012 & 0.000 & 0.000 & 0.008 \\
AFQT & 0.075 & 0.058 & 0.343 & 0.262 \\
Family income & 0.075 & 0.027 & 0.162 & 0.076 \\
Unobserved Heterogeneity & & & 0.339 & 0.487 \\
All of the above & 0.150 & 0.089 & 0.643 & 0.659 \\
\hline \hline
\end{tabular}

R-squares from regressions where variables are individually considered.

Dependent variables in column heading. All regressions include initial grade. 
Table 7: Marginal Effects of Family Income and AFQT scores on Educational Attainment - Comparison of Models

\begin{tabular}{lccccc}
\multicolumn{3}{c}{ Income } & \multicolumn{3}{c}{ AFQT } \\
\hline 1979 & 1997 & $1997-1979$ & 1979 & 1997 & $1997-1979$ \\
\hline
\end{tabular}

Single Type Model

\begin{tabular}{|c|c|c|c|c|c|c|}
\hline \multicolumn{7}{|c|}{ Grade Transition Probability } \\
\hline Age 18 & $0.012^{*}$ & $0.008^{*}$ & -0.004 & $0.024 *$ & $0.023^{*}$ & -0.001 \\
\hline Age 20 & $0.023^{*}$ & $0.016^{*}$ & -0.007 & $0.075^{*}$ & $0.058^{*}$ & $-0.017^{*}$ \\
\hline Age 22 & $0.009 *$ & 0.007 & -0.002 & $0.047^{*}$ & $0.040 *$ & -0.007 \\
\hline \multicolumn{7}{|c|}{ Highest Grade Completed } \\
\hline Age 18 & $0.014^{*}$ & $0.015^{*}$ & 0.001 & $0.025^{*}$ & $0.044^{*}$ & $0.019 *$ \\
\hline Age 20 & $0.080 *$ & $0.057^{*}$ & -0.022 & $0.244 *$ & $0.196 *$ & $-0.047^{*}$ \\
\hline Age 22 & $0.1281^{*}$ & $0.095^{*}$ & -0.033 & $0.433^{*}$ & $0.360 *$ & $-0.074^{*}$ \\
\hline Age 25 & $0.147^{*}$ & $0.115^{*}$ & -0.032 & $0.542 *$ & $0.506^{*}$ & -0.036 \\
\hline \multicolumn{7}{|c|}{ College Attendance } \\
\hline \multirow[t]{2}{*}{ Age 25} & $0.038^{*}$ & $0.023^{*}$ & -0.015 & $0.127^{*}$ & $0.081^{*}$ & $-0.046^{*}$ \\
\hline & \multicolumn{6}{|c|}{ 10-type Model } \\
\hline \multicolumn{7}{|c|}{ Grade Transition Probability } \\
\hline Age 18 & $0.010^{*}$ & 0.007 & -0.003 & $0.022 *$ & $0.021^{*}$ & -0.001 \\
\hline Age 20 & $0.012^{*}$ & 0.004 & -0.008 & $0.050 *$ & $0.016^{*}$ & $-0.034^{*}$ \\
\hline Age 22 & $0.005^{*}$ & 0.000 & -0.004 & $0.035^{*}$ & 0.008 & $-0.026^{*}$ \\
\hline \multicolumn{7}{|c|}{ Highest Grade Completed } \\
\hline Age 18 & $0.021^{*}$ & 0.017 & -0.004 & $0.042 *$ & $0.053^{*}$ & 0.011 \\
\hline Age 20 & $0.049 *$ & 0.022 & -0.027 & $0.162 *$ & $0.084^{*}$ & $-0.077^{*}$ \\
\hline Age 22 & $0.065^{*}$ & 0.027 & -0.038 & $0.254^{*}$ & $0.116^{*}$ & $-0.138^{*}$ \\
\hline Age 25 & $0.073^{*}$ & 0.027 & -0.046 & $0.324 *$ & $0.143^{*}$ & $-0.181^{*}$ \\
\hline \multicolumn{7}{|c|}{ College Attendance } \\
\hline Age 25 & $0.014^{*}$ & 0.003 & -0.011 & $0.064 *$ & $0.015^{*}$ & $-0.049 *$ \\
\hline
\end{tabular}

Note: * signifies statistical significance at the 5 percent level. 
Figure 1. Proportion of sample with a grade increment, by age and NLSY cohort.

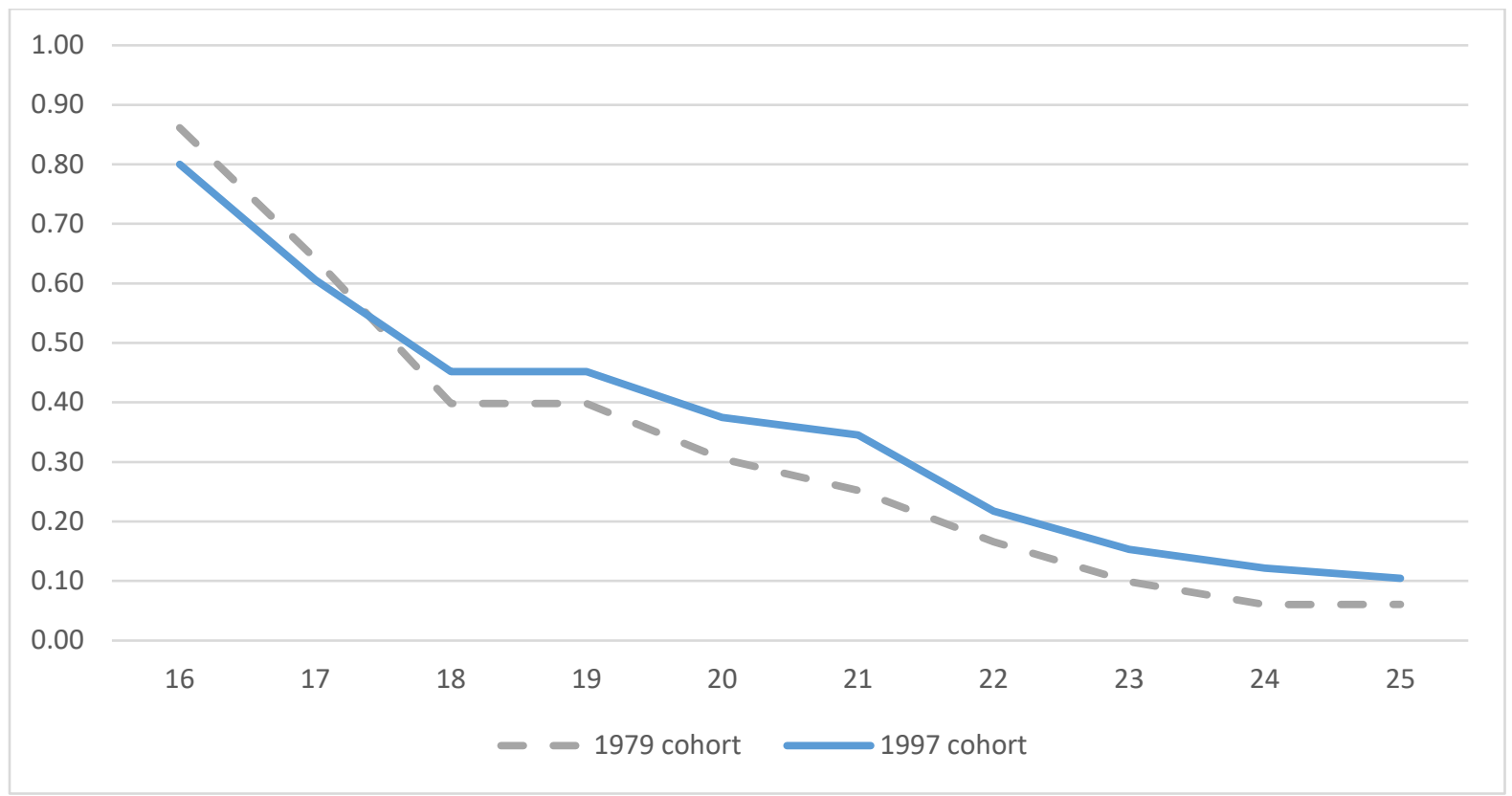

